\title{
Alethic pluralism for pragmatists
}

\author{
Tom Kaspers ${ }^{1,2}(1)$
}

Received: 16 December 2020 / Accepted: 19 December 2021 / Published online: 28 February 2022 (c) The Author(s) 2022

\begin{abstract}
Pragmatism and the correspondence theory of truth are longtime foes. Nevertheless, there is an argument to be made that pragmatists must embrace truth as correspondence. I show that there is a distinctive pragmatic utility to taking truth to be correspondence, and I argue that it would be inconsistent for pragmatists to accept the utility of the belief that truth is correspondence while resisting the premise that this belief is correct.

In order to show how pragmatists can embrace truth as correspondence, I develop a kind of alethic pluralism, which treats pragmatist truth as theoretically fundamental to truth as correspondence. This theoretical fundamentality of pragmatist truth allows the pragmatist to conditionally accept truth as correspondence for certain discourses without falling prey to the typical pragmatist objections to correspondence. This pluralist account of truth thus allows pragmatists to concede that, for certain domains of discourse, truth is correspondence, without thereby betraying their pragmatist principles.
\end{abstract}

Keywords Pragmatism $\cdot$ Alethic pluralism $\cdot$ Truth $\cdot$ Correspondence

\section{Introduction}

If there is one thing a traditional pragmatist loathes, it is the correspondence theory of truth. The rejection of truth as correspondence lies at the roots of the pragmatist tradi-

Tom Kaspers

tk70@st-andrews.ac.uk

1 Department of Philosophy, University of St Andrews, St Andrews, Scotland

2 Department of Law \& Philosophy, University of Stirling, Stirling, Scotland 
tion. Take, for instance, Peirce's attitude towards truth as correspondence, described here by Cheryl Misak:

When Peirce turns his pragmatic maxim on the concept of truth, the upshot is an aversion to "transcendental" accounts of truth, such as the correspondence theory ... For the very idea of the believer-independent world, and the items within it to which beliefs or sentences might correspond, seems graspable only if we could somehow step outside our corpus of belief, our practices, or that with which we have dealings ... We shall see that this [rejection of correspondence] is a persistent theme throughout the pragmatist tradition. (2013, p. 35)

When described as such, the correspondence theory of truth seems to violate any kind of pragmatism whatsoever, since endorsing such a "transcendental" standard for correctness means committing oneself to a standard which implies a departure, per impossibile, from our practices and from "that with which we have dealings".

The connection between pragmatism and the rejection of correspondence is so strong, that Douglas McDermid argues, in his book The Varieties of Pragmatism, that, by looking into the different objections to the correspondence theory, one can give a unified account of pragmatism as a whole. McDermid identifies two general kinds of objections which he calls "the comparison objection" and the "constructivist objection". He shows that the first objection is made in some way by virtually all major pragmatist philosophers, whereas the second objection is a common feature only of the neo-pragmatists, such as Putnam, Davidson, and Rorty. (McDermid, 2006) The comparison objection - which could also be found in Peirce's concerns as described by Misak in the quoted passage above - consist in the worry that aiming for correspondence is pointless, because we can never find out whether we have hit or missed our target. It would only make sense to aim for correspondence if we could somehow transcend our own perspective and compare our beliefs to the believerindependent world. Even if we do manage to have our thoughts correspond to reality, this would be a hollow victory, since we could never know it to be the case. Ordinarily, we take certain features, such as predictive success, to be (fallibly) indicative of representational success, but, as Richard Rorty likes to point out, "[p]erhaps the gods see things otherwise. Perhaps they are amused by seeing us predicting better and better while picturing worse and worse." (1990, p. 155) It would therefore be arrogant for us mortals to assume that we could keep a rein on correspondence tight enough for it to be something we could meaningfully aim at.

While the comparison objection makes the argument that we can never know whether we accurately represent what the world is really like, and that it would thus be futile to aim for representational accuracy, the constructivist objection is that we cannot even make sense of the very idea of there being a world "out there" that has intrinsic features that we can try to represent. Whichever reality our theories construct, they construct it in relation to our practices. Different practices will lead to different conceptual schemes and, in the words of Hilary Putnam, there is no "fact of the matter as to which of the conceptual schemes ... is "really true."”' $(1987$, p. 69) For such a fact could only be formulated from an Archimedean point outside of our practices, which would necessarily be in conflict with pragmatism. 
In this article I argue that the belief that truth is correspondence has a bearing on our practices, by showing that the rejection of this belief leads to a higher degree of stubbornness in the face of disagreement. This stubbornness is a theoretical vice for some domains of discourse, such as scientific domains of discourse, but not necessarily for other domains, such as discourse on matters of taste. From this I argue that, for these former domains of discourse, pragmatists must accept that truth is correspondence. Yet, pragmatists do not have to accept this for the latter domains of discourse, and therefore pragmatists can, and should, become pluralists about truth, by accepting correspondence only for those domains for which doing so is pragmatically advantageous, and by accepting a pragmatist notion of truth for all other domains. I argue that by endorsing pluralism about truth, pragmatists can overcome the abovementioned comparison and constructivist objections.

Given that I argue in this article that pragmatists do not have to endorse these objections and that they neither have to reject truth as correspondence, I could not follow McDermid in basing my characterization of pragmatism on the various objections against the correspondence theory of truth. Instead, I shall rely on a more neutral characterization of the pragmatist doctrine that does not involve the notion of truth at all, but that focusses on the pragmatist methodology, as captured by Charles Sanders Peirce's pragmatic maxim. Peirce primarily takes pragmatism to be a philosophical method for obtaining a "third grade of clearness" by showing the practical bearings of the objects of our conception:

Consider what effects, which might conceivably have practical bearings, we conceive the object of our conception to have. Then, our conception of these effects is the whole of our conception of the object. (Peirce, 1878, p. 293)

As pragmatists, we must always keep in mind the practical consequences of our hypotheses. If it turns out that an entity, claim, or theory has no bearing on our practices, then the pragmatist must argue that it cannot be made sense of. The two objections to the correspondence theory above are meant to show precisely this, that correspondence has no bearing on our practices. I argue, in Sect. 2, that the belief that truth is correspondence does have a practical bearing after all, and that this belief is actually pragmatically advantageous. Section 3 discusses the possible response of calling this belief that truth is correspondence a "useful fiction" and argues that this response is not available to the pragmatist, and that therefore pragmatists must accept that, at least for some domains of discourse, truth is correspondence. Section 4 is devoted to finding a way for pragmatists to accept truth as correspondence. I argue that this entails giving up on monism about truth and endorsing alethic pluralism. I show that the pragmatist can accept correspondence, for some domains of discourse, without falling prey to the abovementioned pragmatist objections, by taking pragmatist truth as methodologically and theoretically fundamental and correspondence as theoretically derivative. The kind of pragmatism that ensues is one that takes correspondence to be a pragmatic commitment. 


\section{The pragmatic value of aiming for correspondence}

Richard Rorty once asked whether, as pragmatists, we can say that, in our inquiry, we aim for truth, rather than justification:

Pragmatists think that if something makes no difference to practice, it should make no difference to philosophy. This conviction makes them suspicious of the philosopher's emphasis on the difference between justification and truth. For that difference makes no difference to my decisions about what to do. If I have concrete, specific, doubts about whether one of my beliefs is true, I can only resolve those doubts by asking if it is adequately justified ... Assessment of truth and assessment of justification are, when the question is what I should believe now ... the same activity. (1995, p. 281)

Rorty's idea is simple: if we want to find out whether our beliefs are true, all we can do is find out whether they are justified, so how could pragmatists believe that inquiry is aimed at truth rather than justification, while these two inquiries are practically identical? Huw Price forcefully argues in "Truth as Convenient Friction" (2003) that it does make a difference to our practices whether we aim for justification or whether we aim for truth. He does this by sketching a thought experiment of a community that does not aim for truth, and he shows that, for this community, all disagreement would be faultless. Disagreement becomes faultless when the participants do not aim for truth, because all they then care about is whether they are themselves justified in their own opinion, and as long as they are, it matters not what one's interlocutor is justified in believing, even if their belief contradicts one's own belief. Yet, once we aim for truth, then the interlocutors would gain an interest in why the other believes something contrary to them, and whether they are justified in doing so, because they know that at most one of them can have a true belief, and this, rather than a mere justified belief, is what they are ultimately after. Price says:

The [truth] norm makes what would otherwise be no-fault disagreements into unstable social situations, whose instability is only resolved by argument and consequent agreement - and it provides an immediate incentive for argument, in that it holds out to the successful arguer the reward consisting in her community's positive evaluation of her dialectical position. (2003, p. 181)

Price has hereby shown the pragmatic value of aiming for truth, and through showing this he has argued that pragmatists must take seriously the idea that inquiry is aimed at truth.

While Price has successfully shown that aiming for truth is pragmatically valuable, I want to take this one step further in the present section and argue that aiming for correspondence can be pragmatically valuable as well.

There seems to be a fairly easy argument for why aiming for correspondence, as opposed to one of the pragmatists notions of truth, would not be pragmatically valuable. Let us take a pragmatist notion of truth, e.g., a Peircean notion of truth as indefeasibly warranted assertibility, and compare it with truth as correspondence. The 
two notions will be materially equivalent, except for evidence-transcendent cases. Evidence-transcendent cases are those cases where disagreement between two theories could not be resolved by bringing in any additional piece of evidence, because both theories are indefeasibly warranted. The correspondence theorist would in these cases be committed to believing that though both theories are indefeasibly warranted, at least one of them is false. Hilary Putnam calls this commitment the commitment to metaphysical realism:

[T] he metaphysical realist claims ... that [an indefeasibly warranted theory] may be, in reality, false. What is not knowable as true may none the less be true; what is epistemically most justifiable to believe may none the less be false, on this kind of realist view. (1983, p. 13)

Putnam argues that pragmatists must reject metaphysical realism. If a theory is an indefeasibly warranted theory, then it is fully pragmatically adequate, and therefore the only way in which it could still be false is a way which would transcend our practices. The belief in a practice-transcendent notion of correctness would be in clear violation of Peirce's pragmatist maxim, because it, by definition, has no bearing on our practices.

In the case that there are two scientists who develop two competing theories, which turn out to both be fully pragmatically adequate, yet conceptually incompatible (because of contradictory ontological commitments for instance), the pragmatist must maintain that the disagreement between the two scientists is faultless. According to Crispin Wright, a disagreement is faultless insofar as neither side of the disagreement is cognitive-procedurally or alethically at fault. (Wright, 2021, p. 2) The first kind of fault is a fault such as a cognitive error (like a miscalculation) or a perceptual error. ${ }^{1}$ The second kind of fault is the fault of one's claims being false.

We cannot say that the disagreement between the scientists must be due to a cognitive-procedural fault, because the theories are both fully pragmatically adequate, so a scientific inquirer could come to accept either one of the theories without having made any cognitive-procedural faults. Nor could we say, as pragmatists, that the disagreement is due to an alethic fault, since if it were, then at least one of the theories would be false in spite of being fully pragmatically adequate, which would be inconceivable for the pragmatist, because this could only be made sense of by employing a practice-transcendent notion of correctness (like correspondence).

How could the pragmatist maintain that neither scientists are alethically at fault? Putnam believes that the solution is to go relativist, by arguing that the two incompatible, yet fully pragmatically adequate, theories are not really incompatible after all, but only appear incompatible because they belong to different conceptual schemes and, as such, they tell different stories about what the world is like. In the summary of "Truth and Convention" Putnam says:

\footnotetext{
${ }^{1}$ According to Misak, Peirce argues that we must always assume, when engaging in inquiry, that the matter of contrasting theories will be resolved one way or another. $(2004$, p. 126) Thus, we must assume that, once we inquire long enough, any disagreement between theories could be resolved by finding some cognitive-procedural fault. Peirce would therefore simply assume that there could never be two competing theories that are both fully pragmatically adequate. I find this assumption implausible.
} 
I discuss a simple case in which theories with different ontologies appear equally adequate in every way ... I contend that the appearance of equal adequacy is correct, and that what this shows is that the notion of "existence" has a variety of different but legitimate uses. (1987, p. 69)

The upshot of this view is the rejection of questions about what "really" exists, or what things are "really" like, independently of our conceptual schemes. In the words of Putnam: "the idea that there is an Archimedean point (or a use of "exist" inherent to the world itself) from which the question "[Which things] really exist" makes sense, is an illusion." $(1987, \text { p. } 71)^{2}$

Putnam's conceptual relativism offers a possible way of showing the disagreement to be alethically faultless, because it shows how the theories could both be true. One theory is true for a particular conceptual scheme, whereas the other is true for another conceptual scheme, so as long as scientists are aware that their theories operate within different conceptual schemes, and they thus use different conceptual schemes for the assessment of their theories, then neither is alethically at fault. ${ }^{3}$ This solution does have the drawback that it must take seemingly incompatible theories to not be incompatible after all. ${ }^{4}$ For those pragmatists who do not want to commit to this, Wright offers another way of avoiding the alethic fault. Wright argues that if one goes deflationist about truth, thereby rejecting the idea that truth is a normative property, then there would be no such thing as an alethic fault. (Wright, 2021) If truth offers no aim or standard for our inquiry, then even if we take our interlocutor to have said something false, we need not take them to be at fault (i.e., in violation of some standard), but we can take them to merely have expressed a thought that is incompatible with what we ourselves believe. ${ }^{5}$

Regardless of whether the pragmatist embraces relativism or deflationism, she must believe that in the case of the disagreement between the two scientists, neither

\footnotetext{
${ }^{2}$ One of my reviewers rightly pointed out that while Putnam's conclusion is metaphysical (there is no ultimate way, intrinsic to the world itself, in which things really exist), the argument is epistemic (we cannot make sense of a notion of correctness that transcends our practices). Such an argument might seem fallacious if we do not keep in mind the Peircean pragmatic maxim which Putnam presupposes: our whole grasp of an entity consists of our conception of the pragmatic effects of the entity. Since the world in and of itself has no pragmatic effects whatsoever, we cannot conceive of it, and therefore we cannot posit its existence either.

${ }^{3}$ Putnam's conceptual relativism, at least on my construal, is a kind assessment-sensitive relativism (like the view argued for by MacFarlane (2014)). It says that the truth of a theory must be assessed from within the appropriate conceptual scheme (instead of from an Archimedean point), and thus it could only be assessed relative to a particular conceptual scheme.

${ }^{4}$ One could wonder, as Wright (2021) does, whether the disagreement between the two scientists is a genuine disagreement at all, on the relativist construal. If we suppose that both scientists are aware that their theories need to be assessed relative to different conceptual schemes, then they need not be in disagreement and can simply accept both theories as true, given their relative conceptual schemes. Conversely, if the scientists are not aware that their theories need to be assessed relative to different conceptual schemes, but instead assess them from within the wrong conceptual schemes, then they are at fault after all, and then the disagreement is not faultless.

${ }^{5}$ Not all deflationists would embrace this solution. For instance, Huw Price would not, because, though he sees himself as a deflationist, he does take truth to be normative (precisely because he wants disagreement to not be faultless). (Price, 2003) As far as I can tell, this is a very uncommon combination of beliefs.
} 
can be cognitive-procedurally at fault or alethically at fault. A consequence of taking their disagreement to be faultless is what Wright calls "sustainability":

Sustainability Neither antagonist need rationally suffer any diminution of confidence in their respective views based purely on finding themselves in disagreement - faultless disagreements are to be examples where, in the terminology of the peer disagreement literature, steadfastness can be an appropriate response. (2021, p. 2)

Steadfastness in one's belief in a theory would be a pragmatically appropriate response in the case of two rival scientific theories that we know to be fully pragmatically adequate. After all, there is no need to search for "the one true theory" for pragmatic purposes, since either theory could be perfectly employed for all such purposes, given that they are fully pragmatically adequate. However, we will never be in a situation in which we know our theories to be fully pragmatically adequate. In ordinary everyday cases, steadfastness is not at all a virtue of science. In fact, in ordinary scientific inquiry, if a scientist refuses to significantly lower the credence of one's belief in one's theory when faced with rival theories that appear equally adequate, then the scientist is not being steadfast, they are merely being stubborn. As philosophers, we often take scientists to be too stubborn in their opinions. Stubbornness is frequently accompanied by scientists giving a higher credence to their theory than they should. They might misinterpret the history of their scientific field as consisting of a linear march towards their own theory. As such, they underestimate the opposing scientists and their rival theories. The problem of the pragmatist response is that it gives scientists a free pass to this kind of behavior.

The pragmatist might object that in ordinary cases the scientist would not know their theory to be fully pragmatically adequate and therefore they cannot assume that the disagreement is faultless. However, the more confident the scientist is, the higher credence they give to the belief that their theory is fully pragmatically adequate, and the likelier they are to be stubborn in their belief, because if they deem it likely that their own theory is fully pragmatically adequate, then they also deem it likely that the rival theory is either determinably worse, or otherwise also fully pragmatically adequate, and in both cases, their stubbornness would be warranted, according to pragmatism at least.

Thus, pragmatism inadvertently offers the overconfident scientist a reason for being stubborn in their belief, which is a bad practical consequence of the view. One might expect metaphysical realism to suffer the opposite drawback, that it makes scientists overly cautious, but this is actually not the case. This is because the lower the credence given to one's theory, the higher the credence of the belief that one's theory is not fully pragmatically adequate, and if it is likely to not be fully pragmatically adequate, then not even the pragmatist would recommend stubbornness, because disagreement is likely to not be faultless. Therefore, the pragmatist would recommend caution to more or less the same degree as the correspondence theorist would, given that the initial credence is reasonably low. The more cautious the scientist initially is, the less it matters whether they are a pragmatist or a correspondence theorist, so endorsing the correspondence theory does not make cautious scientists overly cautious. 
I have shown that the belief that a fully pragmatically adequate theory cannot be false can be disadvantageous to our scientific practices. It does not follow from this that this belief is incorrect, but it does follow that - provided that we are not, and probably never will be, closing in on the end of inquiry (that the unknown will always outweigh the known) - it might be better for our scientific practices if scientists believe in metaphysical realism instead. Therefore, it might be best for our scientific inquiry that it is aimed at a practice-transcendent notion of correctness. It is in this way that aiming for a practice-transcendent notion of correctness has advantageous practical consequences.

\section{Correspondence as a useful fiction}

All I have achieved thus far is that I have shown that, regardless of the pragmatist's aversion towards correspondence, she must admit that there can be a pragmatic value to believing that our statements or our theories correspond to reality. Yet, saying that it is useful to believe that truth is correspondence is a far cry from saying that truth actually is correspondence, right?

Prima facie, the pragmatist could simply give the following reply: we should not accept correspondence, but in order for certain practices to run smoothly, it would be useful to act as if we believe that truth is correspondence. The proponent of this approach might thus say that correspondence is a merely a useful fiction.

However, pragmatism might risk blurring this distinction between what is useful and what we are to accept. Take, for instance, James's characterization of truth as usefulness, or Rorty's view that we must simply accept what works for us. This utility-based kind of pragmatism, which Misak (2013) has shown to be one of two major strands in the pragmatist tradition, seems, at its least sophisticated moments, entirely incapable of accounting for the phenomenon of useful fictions. However, Misak shows that James was, at times, more careful in his writings on truth and made the distinction between what is useful for particular people in particular situations and what proves to be generally beneficial to our practices and to our community as a whole. (Misak, 2013) This would allow him to at least distinguish between lying (which is essentially the simplest form of a useful fiction) and being truthful; lying can sometimes be good for certain people, but it can never be generally beneficial in a way that would prompt us to think of lying as a general principle of good conduct for our practices. ${ }^{6}$

Yet, this would not suffice to show that correspondence is a useful fiction, since I have argued above that, for some of our practices, it would be rational to incorporate the principles of metaphysical realism as general principles which should guide

\footnotetext{
${ }^{6}$ One of my reviewers argued that this move towards a more general utility would not help James, and I agree. For instance, James's view cannot vindicate all instances of the equivalence schema ( $p$ is true iff $p$ ), since, for example, though it is probably the case that it is useful for our practices to accept that strawberries are poisonous if and only if strawberries are poisonous, we could imagine a counterfactual community living in a world in which, unbeknownst to this community, the picking of strawberries would disrupt the ecosystem and set an ecological disaster in motion, so that, for this community, it would be useful for their practices to accept that strawberries are poisonous even if strawberries are not actually poisonous.
} 
one's actions and beliefs, namely which should guide which credence one might give to one's belief in a theory. Here is a telling quote by Schiller-who also belongs to this first strand of pragmatism that urges us to accept what works - in which he talks about the utility of a common-sense realism:

[Realism] manifestly is a theory of very great pragmatic value. In ordinary life we all assume that we live in an 'external' world, which is 'independent' of us ... And it would be a great calamity if any philosophy should feel it its duty to upset this assumption. For it works splendidly ... for almost every purpose. (1907, p. 459)

If my arguments work, then this would also hold true for the belief that truth is correspondence, at least for some domains of discourse, and therefore there would be a general pragmatic value to aiming for correspondence. The pragmatic value of believing truth to be correspondence is not incidental, but it is generally advantageous to have this belief in place to safeguard ourselves from stubbornness, so pragmatists like Schiller or James could not treat it as a useful fiction.

The reader might object that surely any serious form of pragmatism must be able to account for the distinction between a belief being generally useful and a belief being true. Luckily, the second strand of pragmatism manages to recover a more robust notion of useful fictions. Christopher Hookway notes that, whereas the Jamesian strand of pragmatism centers its conception of truth around notions such as usefulness, the Peircean strand of pragmatism centers its conception of truth around epistemic notions, like 'knowledge', 'evidence', 'warrant', and 'inquiry'. (Hookway, 2007) Thus, we should not be inclined to take a belief to be correct if there would merely be a prudential value to doing so; the belief would have to be of epistemic value, i.e., it would have to be beneficial for our inquiry. It is only when a belief is required in order for our inquiry to be carried out in the way in which we think it ought, that we must take this belief to be true, rather than merely a useful fiction. Such beliefs are what Peirce calls "regulative assumptions", i.e., something "that we have to assume [is] true if we are to carry on in the way it seems that we must carry on." (Misak, 2013, p. 28).

However, once again, this would not be enough to treat correspondence as merely a useful fiction, because I have shown above that the incorporation of the belief in correspondence into some of our practices would also be distinctly useful for our inquiry, e.g., it can help the overconfident scientist to derive a more accurate credence for their theoretical beliefs and consequently to not overlook rival theories. Therefore, for some discursive practices, believing truth to be correspondence would be epistemically beneficial. It could indeed be called a regulative assumption for science: if we are to carry out our scientific inquiry in the way we think it should be carried out, then we must take this inquiry to aim for correspondence.

I have now shown that the usual versions of pragmatism cannot take the belief in correspondence to be a useful fiction, but, as one of my reviewers pointed out, I am currently leaving open the possibility that another version of pragmatism will be developed, or that unbeknownst to me it already exists, which does have the resources for treating correspondence as a useful fiction. Therefore, some more general reflec- 
tions are needed to show that treating correspondence as a useful fiction makes no sense.

In general, it seems that there are only two types of cases in which one is justified in treating a theory or belief as a useful fiction. The first case is when the theory cannot be made sense of; when it is strictly speaking nonsense, but when it is nevertheless useful nonsense. The pragmatist would want to argue that this applies to correspondence. They would argue that, though believing in correspondence might be useful, correspondence is "empty metaphysics". The reason for it being empty metaphysics is that it allegedly has no bearing on our practices, and thus the belief in correspondence is confused and devoid of content. However, the pragmatist cannot argue that this belief is devoid of content if it is pragmatically relevant, i.e., if it is connected to clear and determinate ways of going about our practices. Since I have shown correspondence to be pragmatically beneficial, it is certainly also pragmatically relevant. ${ }^{7}$

The other case in which one is justified in treating a theory or belief as a useful fiction is when the theory or belief can be shown to be 'flawed', 'incorrect', or 'lacking'. I have already shown that pragmatists struggle to show how, given their own standards of correctness, correspondence could be seen as flawed or incorrect in spite of being, generally and epistemically, beneficial to some of our practices. Since it is the case that, for some of our practices, it is generally and epistemically beneficial to aim for a practice-transcendent standard of correctness, it is the case that a practicetranscendent notion of correctness is pragmatically adequate for these practices. So, in what way would this notion of correctness be flawed? It could only be flawed in a way that eludes our practices, since it is, after all, pragmatically adequate; if correspondence is pragmatically adequate, a practice-transcendent standard of correctness is needed in order to show it to be incorrect. Of course, the pragmatist would ordinarily argue against a practice-transcendent standard of correctness by showing that it is pointless to aim for this in our practices, yet I have argued for the utility of this aiming in the previous section, so the only way for the pragmatist to still show transcendental notions of correctness to be flawed is by employing a transcendental notion of correctness herself, which would of course be plainly inconsistent. This inconsistency would trouble any kind of pragmatist who tries to resist the move from the pragmatic adequacy of practice-transcendent notions of correctness to the acceptance of these notions. Thus, for the pragmatist, correspondence cannot be a useful fiction.

\section{Pragmatist alethic pluralism}

I have shown above that it can be beneficial to our practices to believe in truth as correspondence. I have argued that the pragmatist cannot accept this pragmatic value of correspondence without accepting that truth actually is correspondence. One might read this as an argument against the internal coherence of pragmatism; after all, the

\footnotetext{
${ }^{7}$ I will restate this point in a bit more detail in the next section, in which I address the constructivist objection.
} 
pragmatist has always maintained that the correspondence theory has no practical bearings, but now it turns out that it not only does have practical bearings, but that it can also be more pragmatically advantageous than pragmatist alternatives. However, I do not think that my arguments show that pragmatism itself is incorrect. Instead, by showing that it can be pragmatically advantageous to accept correspondence, the arguments indicate that correspondence can be incorporated into pragmatism without there being an internal incoherence. In this current section, I argue that this can be done by adopting a particular pluralist framework for truth. I argue for this by showing that this pluralist framework enables pragmatists to accept correspondence for some domains of discourse without falling prey to the pragmatist objections to the correspondence theory.

In order to do this, we must let go of monism about truth; we must deny that our concept of truth picks out the same property for all our discourse. By doing so, we would no longer need to take my arguments to show that pragmatists must accept correspondence across the board, but only that they must accept correspondence whenever it is pragmatically advantageous to do so. This might be the case for science, for instance, but need not be the case for aesthetics. In fact, while we should take issue with a pragmatist notion of truth for scientific discourse, because it can render the disagreement between scientists faultless and thereby promotes stubbornness, this would not be a problem for aesthetic disagreement, which we already assume to be faultless anyways, and for which steadfastness is appropriate. Therefore, it would not be practically advantageous to take truth to be correspondence for aesthetics. In the case that there is no pragmatic value to taking truth to be correspondence, the pragmatist need not accept correspondence, so, if we suppose that pragmatists only accept that truth is correspondence if it has this pragmatic value, we can say the following:

(Correspondence) $\operatorname{Truth}_{\mathrm{D}}{ }^{8}$ is correspondence if and only if we are pragmatically committed to taking truth ${ }_{\mathrm{D}}$ to be correspondence.

Applying the equivalence schema (" $p$ " is true if and only if $p$ ) to the left side of this biconditional gives us something that looks like a definition of truth for the metalevel truth-assigning claim "Truth ${ }_{\mathrm{D}}$ is correspondence":

(Metalevel) "Truth ${ }_{\mathrm{D}}$ is correspondence" is true if and only if we are pragmatically committed to taking truth ${ }_{\mathrm{D}}$ to be correspondence.

This seems to imply that the truth of metalevel statements that assign truth properties to domains of discourse consists in pragmatic utility, since the statement has the following form: " $p$ " is true if and only if accepting $p$ is pragmatically advantageous. The notion of truth that governs these metalevel claims would therefore be some kind of pragmatist notion of truth.

\footnotetext{
${ }^{8}$ Truth $_{\mathrm{D}}=$ truth for a domain of discourse D.
} 


\subsection{Two pragmatist interpretations of (Metalevel)}

The first strand of utility-based pragmatism, mentioned in the last section, can readily accept (Metalevel) as stating that the notion of truth ranging over truth-assigning statements is grounded in utility. However, the second, epistemic, strand of pragmatism would reject a utility-based notion of correctness and would rather accept an epistemic notion of correctness. There is another possible interpretation of (Metalevel) which might suit this latter kind of pragmatist; it involves adopting a kind of metalinguistic expressivism about the truth-assigning claim on the left-hand side, by arguing that the right-hand side of the biconditional states what the claim on the left-hand side expresses. On this interpretation, a statement like "Truth ${ }_{D}$ is correspondence" would not offer a description, but an expression of a pragmatic commitment. This kind of metalinguistic expressivism is inspired by Carnap's treatment of ontological discourse not as descriptive of reality but as expressive of covertly metalinguistic norms about how to engage with different discursive practices. (Kraut \& Scharp, 2015) Obviously, if "Truth ${ }_{D}$ is correspondence" expresses a pragmatic commitment, then this statement is true if and only if we are in fact pragmatically committed to taking truth ${ }_{\mathrm{D}}$ to be correspondence, so (Metalevel) holds.

It is important, for the purposes of figuring out which discourses are committed to truth as correspondence, to keep in mind that this commitment is a pragmatic commitment — one must only accept correspondence if it is pragmatically beneficial to do so - and that therefore the acceptance of correspondence must be vindicated on pragmatic grounds, not on ontological grounds. It is in this sense that, according to pragmatists like Schiller, James, and Quine, "the world" or "reality" is postulated rather than discovered, since we only take "the world" to dictate what is true and what is false if it is pragmatically advantageous to do so. (McDermid, 2006) However, McDermid is right to note that "to call $x$ a posit is not ipso facto to impugn $x$ 's ontological credentials or status." (2006, p. 80) Thus, these pragmatists are not saying that the world does not really exist independently of us, but they instead argue that this distinction between what exists independently of us and what does not (this is sometimes called the Bifurcation Thesis), is itself postulated by us. In the words of Robert Kraut, "[o]ne might object to BT [bifurcation thesis] if it were committed to some practice-transcendent ontological 'ground' for its distinctions; but such baggage is no essential part of BT." (1990, p. 180) Thus, pragmatists make a distinction between what exists independently of us and what does not-i.e. between domains of discourse in which truth is correspondence and domains in which it is not - not because they think that this distinction itself offers an accurate description of the way things are, but because making this distinction is beneficial to our practices, and as such we are pragmatically committed to it. The pragmatist Bifurcation Thesis is therefore not descriptive but it is expressive of pragmatic commitments. ${ }^{9}$

As a result, decisions as to where to place the bifurcation ought to involve all of our practices; the benefits and costs of adopting correspondence as truth for a domain

\footnotetext{
${ }^{9}$ I believe that all philosophical theses are expressive of practical commitments, instead of descriptive of reality. I call this view "metaphilosophical expressivism". Sadly, I cannot say more about this in this current article, without it taking us too far afield.
} 
of discourse should be conceived holistically, not separately for each particular discourse. This is also expressed by Kraut, once we interpret "descriptive" discourse as discourse which has correspondence as a truth property and "projective" discourse as all other discourse:

[I]t should be clear that holism lurks in the [bifurcation thesis] no less than it lurks anywhere else. Decisions as to which discourse is descriptive and which projective obviously depend upon constraints provided elsewhere in our theorizing, and those decisions can be reversed in light of subsequent developments. (1990, pp. 180-181)

One could conceive of the task of bifurcating our domains of discourse as arranging our conceptual furniture. We need to find the optimal arrangement for these pieces of furniture, but we know that we cannot fit everything inside, so some stuff will have to be relegated to the outside. Some pieces of furniture are clearly best equipped for the outside, but sometimes it is less clear what to keep inside and what to drag outside. Thus, we try out different arrangements until we reach "the perfect" arrangement. Of course, once we hit upon the optimal arrangement, we might not realize that we have done so, as there might not be a decisive moment in which it will be clear to us that we have achieved what we set out to do. Furthermore, the pragmatist would want to deny that there is a special arrangement which we are destined to end up with, as if this arrangement were correct in virtue of a predetermined mind-independent fact (for they reject that the bifurcation thesis can be justified on independent ontological grounds). Rather, the optimal arrangement would simply be the one that will not be improved upon. Therefore, the correct arrangement is best seen as one that is indefeasibly warranted.

As I have shown, (Metalevel) can be interpreted either in a way that would have us endorse a utility-based notion of truth for truth-assigning claims like "Truth ${ }_{D}$ is correspondence", or in a way in which these truth-assigning claims express pragmatic commitments and are true in virtue of an epistemic notion of truth. Both interpretations fall within the realm of pragmatism and provide us with a moderate pragmatist theory that takes our commitment to correspondence to be a pragmatic commitment, so that the world and its entities are both, in a sense, postulated and real.

\subsection{The comparison objection and the constructivist objection}

I believe that this kind of pragmatist framework can help to dispel the comparison and constructivist objections to correspondence mentioned at the start of this paper. Let us first look at the comparison objection, which consists in saying that it is pointless and arrogant to try to aim for correspondence, because it would be impossible for us to ever know whether, or to what extent, this aim has been achieved. The response to this would be to say that, though it might be arrogant to assume correspondence, it would not always be pointless to do so. The mistake the pragmatist voicing this concern makes is that she neglects the possibility that the aiming could itself be pragmatically valuable even if what is aimed for is useless. Aiming for correspondence can be pragmatically valuable, because the way we act when we aim 
for correspondence has pragmatic benefits. By accepting that a pragmatist notion of truth ranges over statements that assign correspondence to domains of discourse, one would accept correspondence only conditionally; one would accept correspondence only if it would not be pointless to do so. Thus, part of the comparison objectionthat it would be pointless to take truth to be correspondence - is already dispelled.

The other part- that it would be arrogant to assume that we are capable of corresponding to reality - can be conceded, though it must be stressed that this is useful arrogance. Were we to actually believe that correspondence is out of our reach, our inquiry would suffer. In this sense, the comparison objection offers little more than what Peirce has called "paper doubts" (Misak, 2013, p. 33); though we are able to appreciate its reasoning from a scholastic point of view, if we were to actually integrate this kind of skepticism into our everyday lives, thereby ceasing to believe that we could ever represent reality, our inquiry would go astray. Therefore, this kind of concern could even be called anti-pragmatist. Insofar as we acknowledge the pragmatic value of correspondence, we should think of the presupposition that our currently held beliefs correspond to reality as, to use that other Peircean term, a regulative assumption. Though we can never step outside of our practices to check whether correspondence actually obtains, we acknowledge that, in order to carry out our inquiry in the way it seems it must be carried out, we must assume that it does, until we have reason to believe otherwise.

The constructivist objection to correspondence is that the very notion of correspondence is a piece of empty metaphysics that is completely detached from our practices. If my arguments above are correct, then this concern is simply mistaken, because the notion of correspondence would have a bearing on our practices. I have shown that there can be a pragmatic value to believing that truth is correspondence, which entails that the belief in correspondence is one that leads to certain ways of acting that are clearly distinguishable from the ways in which one who rejects correspondence, or one who ignores correspondence altogether, would act. Therefore, correspondence satisfies the Peircean criterion for meaningfulness: "there is no distinction of meaning so fine as to consist in anything but a possible difference of practice." (1878, p. 293) However, we could accept that if correspondence were to lack its pragmatic value, then it would be a meaningless artefact of empty metaphysics. Yet, because the pluralist account takes the notion of correctness for the assignments of truth properties to be a pragmatist notion, correspondence cannot exist without its pragmatic value.

\subsection{Some features of pragmatist alethic pluralism}

I have argued that the belief in correspondence is pragmatically valuable because it safeguards against the stubbornness of inquirers. However, while this is valuable for scientific discourse, it does not appear to be particularly valuable for, say, aesthetic discourse, because we believe that aesthetic disagreement, as opposed to scientific disagreement, is faultless, and therefore we can be steadfast in our aesthetic beliefs, which means that stubbornness is warranted (to a certain extent). (Correspondence) tells us that "Truth ${ }_{\mathrm{D}}$ is correspondence" is true only if we are pragmatically committed to taking truth $\mathrm{D}_{\mathrm{D}}$ to be correspondence. Yet, we are not pragmatically committed 
to taking aesthetic truth to be correspondence, because doing so would not be pragmatically advantageous. Therefore, (Correspondence) tells us that truth for aesthetic discourse cannot be correspondence. In this way, (Correspondence) leads us to pluralism about truth (or to dualism at least). But what might a pragmatist version of alethic pluralism look like?

In order to figure out which kind of alethic pluralism a pragmatist could embrace, it is useful to divide up the pluralist accounts of truth, as Kellen (2018) does, into two camps: those that treat correspondence as methodologically fundamental and those that treat a pragmatist notion of truth as methodologically fundamental. According to Kellen, many contemporary accounts of alethic pluralism treat correspondence as methodologically fundamental, which means that they take correspondence as their default notion of truth. This implies that, for these theories, in order to say that truth for a domain of discourse is some other property than correspondence, one would have to argue why correspondence would be inappropriate for this domain (for instance by saying that correspondence would lead to undesirable metaphysical consequences). For pragmatists, this must seem like it gets things the wrong way round. If pragmatists are to accept correspondence at all, it must be shown how they can build their way up to it while adhering to pragmatist principles; the pragmatist would not accept correspondence unconditionally.

However, the originator of alethic pluralism, Crispin Wright, does share the pragmatists' methodological conviction. He argues that since anti-realism is the less committing position, we should take it as the default, and we should only be inclined to go realist about a domain of discourse (thereby taking truth to be correspondence) if there are strong indications that anti-realism would not suffice. (Wright, 1992) Moreover, Wright's main notion of anti-realist truth, superassertibility - which is roughly indefeasibly warranted assertibility - comes very close to a Peircean pragmatist account of truth. In Misak's words:

It might now seem that there is no difference at all between Wright and the pragmatist ... both think that what it is for a belief to be true is that it would not be improved upon, that it would forever be assertible. (1998, p. 414)

What is warranted at the end of inquiry is also indefeasibly warranted, and what is indefeasibly warranted is also warranted at the end of inquiry, so Wright's superassertibility and Peircean truth are very close indeed. Since Wright's superassertibility can be accepted as the pragmatist notion of truth for the epistemic strand of pragmatism, his account of alethic pluralism could serve as the basis for a pragmatist alethic pluralism.

However, unlike Wright's pluralism, pragmatist pluralism would also take pragmatist truth to be theoretically fundamental. According to Kellen, if a pluralist account takes one truth property to be theoretically fundamental to another truth property, then it takes these properties to be linked in such a way that in order to understand the latter one must have already grasped the former. (Kellen, 2018) This holds for correspondence on the pragmatist account, because of the constructivist objection: if correspondence were to lack its pragmatic value, then it would be a meaningless artefact of empty metaphysics. In other words, the metalevel claims such as "Truth 
is correspondence" need to be true, in the pragmatist sense, for us to be able to make sense of correspondence at all. It is in this sense that correspondence is theoretically dependent on pragmatist truth; correspondence can only be made sense of if the relevant metalevel claims ("Truth ${ }_{\mathrm{D}}$ is correspondence") are true in the pragmatist sense of truth.

The theoretical dependence of correspondence on pragmatist truth would be a unique feature of an account of alethic pluralism, according to Kellen:

As of now, there is no truth pluralism in the literature which treats anti-realism as theoretically fundamental ... Nevertheless, it seems to be a conceptually possible account of truth. (2018, p. 138)

One could generalize (Correspondence) above in order to derive the general pragmatist mechanism for assigning truth properties:

(Truth) Property $x$ is truth for domain D if and only if we are pragmatically committed to taking $x$ to be truth for D.

An interesting question, asked by one of the reviewers, is whether (Truth) commits us to moderate pluralism. Within the field of alethic pluralism, most philosophers endorse a "moderate" alethic pluralism, e.g., Lynch (2008) or Edwards (2018), because they believe that, in addition to there being multiple domain-specific truth properties, there is also a general truth property, which can be described by the various platitudes about truth, such as: truth is the goal inquiry, " $p$ " is true if and only if $p$, to assert $p$ is to present $p$ as true, etc. (Wright, 1992, p. 34) (Edwards, 2013, p. 116) Those who believe that there is this general truth property, in addition to the domain-specific truth properties, are called moderate pluralists, and those who do not are called strong pluralists. The main challenge for moderate pluralists is to explain the relation between general truth and the domain-specific truth properties (and to show how the former does not make the latter redundant). The main challenge for the strong pluralist is to make sense of truth for mixed discourse, i.e., discourse that involves multiple domains, such as the conjunction $p \& q$, where $p$ belongs to a domain for which truth is correspondence and $q$ belongs to a domain for which truth is superassertibility. (Tappolet, 1997)

Does (Truth) entail a general truth property? At a first glance, (Truth) might lead to (Truth*) below, in which case there would be a general truth property for $p$ : the property of being practically committed to $p$.

(Truth*) $p$ is true if and only if we are pragmatically committed to taking $p$ to be true.

However, it is very important to see that (Truth) does not actually lead to (Truth*). For instance, we might be pragmatically committed to taking a scientific theory to be true, but since we are also pragmatically committed to taking truth for scientific discourse to be correspondence, we are pragmatically committed to the possibility 
that a scientific theory that we are pragmatically committed to might really be false. Hence, we would have to deny (Truth*).

Therefore, accepting (Truth) does not seem to point us towards moderate pluralism. Yet, it does not point us away from moderate pluralism either, since (Truth) is not incompatible with general truth. For instance, we could support a version of Douglas Edwards' Determination Pluralism (2018), by slightly amending (Truth), so that it becomes (Truth-Determining):

(Truth-Determining) Property $x$ is a truth-determining property for domain D if and only if we are pragmatically committed to taking $x$ to be a truth- determining property for $\mathrm{D}$.

Edwards uses an analogy with winning a game to explain his theory: the property of winning a game is always the same (namely the property that is the goal of the game), but the property that determines who wins a game differs depending on which game is played. Similarly, the property of truth is a single general property, but the property that determines what is true differs depending on the domain of discourse. (2018, p. 125) On this account, truth could simply be the property that is the goal of inquiry, which is a single general property, and (Truth-Determining) would not pick out different truth properties, but it would pick out different properties that determine for particular domains of discourse whether the goal of inquiry has been reached. For instance, what it is to reach the goal of scientific inquiry (i.e., what it is for a scientific assertion to be true) is to correspond to reality, so correspondence is the truth-determining property for scientific discourse.

\section{Conclusions}

I have argued that pragmatists should accept truth as correspondence for some domains of discourse. They should do so because it is pragmatically advantageous for some of our discursive practices, like our scientific practices, if they aim at a practice-transcendent notion of correctness. Furthermore, I have argued that the belief in correspondence is, for certain practices, both generally and epistemically beneficial, which is why this belief in correspondence is pragmatically adequate for these practices. Pragmatists cannot treat the belief in correspondence as a useful fiction, because they cannot show correspondence to be incorrect without employing a practice-transcendent standard of correctness, which would render their argument inconsistent. What this argument shows is that pragmatists must say that truth for a domain of discourse is correspondence if (and only if) they are pragmatically committed to taking it to be so.

This conditional acceptance of correspondence can be rephrased in a way that gives rise to a pragmatist interpretation of the truth of the metalevel, truth-assigning, statement "Truth ${ }_{D}$ is correspondence". I have shown that truth for this kind of statements could consist either in a utility-based notion of truth or in an epistemic notion of truth. The pluralist account of truth that follows from this framework is one that takes pragmatist truth to be theoretically fundamental to correspondence, which 
makes it unlike other accounts of alethic pluralism. I have shown that by endorsing this account of truth, the pragmatist does not have to shy away from correspondence.

Acknowledgements I am very grateful to my supervisor Crispin Wright for his guidance and to everyone involved with the Virtual International Consortium in Truth Research (VICTR) for helping me organize a work-in-progress session where I received useful feedback from many attendees. I would also like to thank Cheryl Misak, Andrew Howat, Kevin Scharp, Jacob LiBrizzi, Yoichi Kobe, Duccio Calosi, Niccolò Aimone Pisano, Nicola Bonatti, Nick Allen, and the anonymous reviewers at Synthese for their extremely useful comments.

Authors' contributions Not applicable.

Funding The author has no relevant financial or non-financial interests to disclose.

Availability of data and material Not applicable.

Code availability Not applicable.

\section{Declarations}

Conflicts of interest/Competing interests No funds, grants, or other support were received.

Open Access This article is licensed under a Creative Commons Attribution 4.0 International License, which permits use, sharing, adaptation, distribution and reproduction in any medium or format, as long as you give appropriate credit to the original author(s) and the source, provide a link to the Creative Commons licence, and indicate if changes were made. The images or other third party material in this article are included in the article's Creative Commons licence, unless indicated otherwise in a credit line to the material. If material is not included in the article's Creative Commons licence and your intended use is not permitted by statutory regulation or exceeds the permitted use, you will need to obtain permission directly from the copyright holder. To view a copy of this licence, visit http:/creativecommons.org/ licenses/by/4.0/.

\section{References}

Edwards, D. (2013). Truth, winning, and simple determination pluralism. In N. J. L. L. Pedersen, \& C. D. Wright (Eds.), Truth and Pluralism: Current Debates (pp. 113-122). Oxford: Oxford University Press

Edwards, D. (2018). The Metaphysics of Truth. Oxford: Oxford University Press

Hookway, C. (2007). Fallibilism and the aim of inquiry. Aristotelian Society Supplementary Volume, 81(1), $1-22$

Kellen, N. (2018). Methodological pluralism about truth. In J. Wyatt, N. J. L. L. Pedersen, \& N. Kellen (Eds.), Pluralisms in Truth and Logic (pp. 131-144). Cham: Palgrave Macmillan

Kraut, R. (1990). Varieties of pragmatism. Mind, 99(394), 157-183

Kraut, R., \& Scharp, K. (2015). Pragmatism without idealism. In C. Daly (Ed.), The Palgrave Handbook of Philosophical Methods (pp. 331-360). London: Palgrave Macmillan

Lynch, M. (2008). Truth as One and Many. Oxford: Oxford University Press

MacFarlane, J. (2014). Assessment Sensitivity: Relative Truth and its Applications. Oxford: Oxford University Press

McDermid, D. (2006). The Varieties of Pragmatism: Truth, Realism, and Knowledge from James to Rorty. London: Continuum

Misak, C. (1998). Deflating truth: Pragmatism vs. minimalism. The Monist, 81(3), 407-425 
Misak, C. (2004). Truth and the End of Inquiry: A Peircean Account of Truth. Oxford: Oxford University Press

Misak, C. (2013). The American Pragmatists. Oxford: Oxford University Press

Peirce, C. S. (1878). How to make our ideas clear. Popular Science Monthly, 12, 286-302

Price, H. (2003). Truth as convenient friction. The Journal of Philosophy, 100(4), 167-190

Putnam, H. (1983). Realism and Reason. Cambridge: Cambridge University Press

Putnam, H. (1987). Truth and convention: On Davidson's refutation of conceptual relativism. Dialectica, $41(-2), 69-77$

Rorty, R. (1990). Representation, social practice, and truth. In R. Rorty (Ed.), Objectivity, Relativism, and Truth: Philosophical Papers (pp. 151-161). Cambridge: Cambridge University Press

Rorty, R. (1995). Is truth a goal of inquiry? Davidson vs. Wright. The Philosophical Quarterly, 45(180), 281-300

Schiller, F. C. S. (1907). Studies in Humanism. London: Macmillan and Co., Limited

Tappolet, C. (1997). Mixed inference: A problem for pluralism about truth predicates. Analysis, 57(3), 209-210

Wright, C. (1992). Truth and Objectivity. Cambridge MA: Harvard University Press

Wright, C. (2021). Alethic pluralism, deflationism and faultless disagreement. Metaphilosophy, 52(3-4), $432-448$

Publisher's Note Springer Nature remains neutral with regard to jurisdictional claims in published maps and institutional affiliations. 